Programa de Pós-graduação em Educação, Universidade Federal do Ceará Fortaleza-CE-Brasil

\title{
Apresentação: Memória e práticas educativas na Educação Profissional e Tecnológica
}

\section{Presentation: Memory and educational practices in Professional and Technological Education}

\section{Presentación: Memoria y prácticas educativas en la Educación Profesional y Tecnológica}

A temática da Educação Profissional e Tecnológica, felizmente, tem ocupado posição que antes não encontrava nos debates acadêmicos no Brasil. Tal importância reside sobretudo no fato de essa modalidade de ensino ter ganho, no atual século, uma projeção que nunca teve na sua história. Partimos de 19 Escolas de Aprendizes Artífices, em 1909, para mais de 659, em 2018, segundo dados do Ministério da Educação'.

A Rede Federal de Educação Profissional, Científica e Tecnológica, criada pela Lei no 11.892/2008, também conhecida por Rede Federal, constituiu-se em um marco na ampliação, interiorização e diversificação da educação profissional e tecnológica no país. Está composta por: I - Institutos Federais de Educação, Ciência e Tecnologia (Institutos Federais); II - Universidade Tecnológica Federal do Paraná - UTFPR; III Centros Federais de Educação Tecnológica Celso Suckow da Fonseca do Rio de Janeiro (Cefet-RJ) e de Minas Gerais (Cefet-MG); IV - Escolas Técnicas vinculadas às Universidades Federais; e V - Colégio Pedro II.

Tal cenário justifica a necessidade do dossiê Memória e práticas educativas na Educação Profissional e Tecnológica ao proporcionar espaços de diálogos acerca de temas relevantes como currículo, processos formativos, experiências na Educação Profissional e Tecnológica, história e memória, dentre outros.

A atualidade do tema do dossiê permitiu uma ampla procura. Recebemos cerca de cem artigos de várias partes do Brasil, dos quais selecionamos aqueles que estavam mais adequados ao nosso escopo. Assim, além dos 24 artigos publicados no último número da Revista Labor, neste número publicamos mais 21 artigos, totalizando 45 nos dois números dessa revista.

${ }^{1}$ Disponível em: http://portal.mec.gov.br/setec-programas-e-acoes/expansao-da-rede-federal Acesso em: 16 dez. 2020. 
Programa de Pós-graduação em Educação, Universidade Federal do Ceará Fortaleza-CE-Brasil

Os 21 artigos desse segundo número do dossiê Memória e práticas educativas na Educação Profissional e Tecnológica apresenta, como no primeiro, uma diversidade de temas e de filiações institucionais dos seus autores, abrangendo as 5 regiões brasileiras. Destacamos também a participação desses autores em vários Programas de Pós-Graduação stricto sensu na condição de docentes e de discentes.

Por fim, gostaríamos de registrar que essas produções se deram num contexto de pandemia, momento em que ficamos (e ainda estamos) vulneráveis física e psicologicamente a esse problema de saúde pública, mas, mesmo assim, resistimos, produzimos, ensinamos, aprendemos, trocando saberes...

Agradecemos às equipes editorial e técnica da Labor pela receptividade em nos atender e nos oportunizar esse espaço de divulgação.

Prof. Dr. Francisco das Chagas Silva Souza (IFRN)

Prof. Dr. Vantoir Roberto Brancher (IFFar)

Dezembro de 2020.

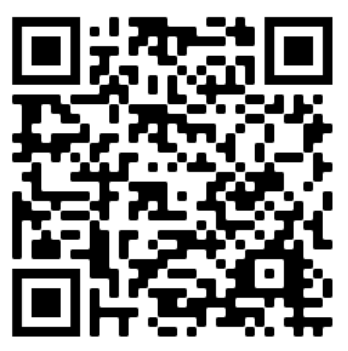

